\title{
INTRAAORTIC BALLOON PUMPING FOR CARDIAC SUPPORT: TRENDS IN PRACTICE AND OUTCOME, 1968 TO 1995
}

David F. Torchiana, MD

Gregory Hirsch, MD

Mortimer J. Buckley, MD

Chiwon Hahn, MD

John W. Allyn, MD

Cary W. Akins, MD

John F. Drake

John B. Newell

W. Gerald Austen, MD
Objectives: A total of $\mathbf{4 7 5 6}$ cases of intraaortic balloon pump support have been recorded at the Massachusetts General Hospital since the first clinical insertion for cardiogenic shock in 1968. This report describes the patterns of intraaortic balloon use and associated outcomes over this time period. Methods: A retrospective record review was conducted. Results: Balloon use has increased to more than 300 cases a year at present. The practice of balloon placement for control of ischemia ( 2453 cases, $11.9 \%$ mortality) has become more frequent, whereas support for hemodynamic decompensation (congestive heart failure, hypotension, cardiogenic shock) has been relatively constant (1760 cases, $38.2 \%$ mortality). Mean patient age has increased from 54 to 66 years, and mortality has fallen from $41 \%$ to $20 \%$. Sixty-five percent $(3097 / 4756)$ of the total patient population receiving balloon support underwent cardiac surgery. Placement before the operation (2038 patients) was associated with a lower mortality $(13.6 \%)$ than intraoperative (771 patients, $35.7 \%$ mortality) or postoperative use (276 patients, $35.9 \%$ mortality). Independent predictors of death with balloon pump support were insertion in the operating room or intensive care unit, transthoracic insertion, age, procedure other than angioplasty or coronary artery bypass, and insertion for cardiogenic shock. Independent predictors of death with intraoperative balloon insertion were age, mitral valve replacement, prolonged cardiopulmonary bypass, urgent or emergency operation, preoperative renal dysfunction, complex ventricular ectopy, right ventricular failure, and emergency reinstitution of cardiopulmonary bypass. Conclusions: Balloons are being used more frequently for control of ischemia in more patients who are elderly with lower mortality. An institutional bias toward preoperative use of the balloon pump appears to be associated with improved outcomes. (J Thorac Cardiovasc Surg 1997; 113:758-69)
Tsersing he intraaortic balloon pump (IABP) represents a successful clinical application of the principle of counterpulsation. ${ }^{1,2}$ IABP support can produce a modest increment in forward output in the injured

From the Department of Surgery, Massachusetts General Hospital, Boston, Mass.

Supported by a grant from St. Jude Medical, Inc., St. Paul, Minn.

Read at the Seventy-sixth Annual Meeting of The American Association for Thoracic Surgery, San Diego, Calif., April 28-May 1, 1996.

Received for publication May 6, 1996; revisions requested July 10, 1996; revisions received Nov. 19, 1996; accepted for publication Dec. 18, 1996.

Address for reprints: David F. Torchiana, MD, Massachusetts General Hospital, Boston, MA 02114.

Copyright $@ 1997$ by Mosby-Year Book, Inc.

$0022-5223 / 97 \$ 5.00+0 \quad \mathbf{1 2 / 6 / 7 9 8 7 8}$ or failing heart, ${ }^{3,4}$ but the most obvious efficacy both theoretically and empirically is in the setting of ischemia resulting from coronary artery disease. With appropriate timing to the cardiac cycle, the IABP can both decrease cardiac work by deflating during systole and reduce afterload and augment coronary perfusion by inflating during diastole. This simultaneous improvement in coronary flow and reduction in myocardial oxygen consumption is a unique benefit of the IABP and other methods of mechanical support.

The first clinical experience with the IABP was in patients with cardiogenic shock after myocardial infarction. $^{5,6}$ Although outcomes were initially poor, with high mortality, significant hemodynamic improvement was documented, which encouraged continued investigation. ${ }^{7}$ In 1972, Buckley, Craven, 
and $\mathrm{Gold}^{8}$ reported 27 cases in which the IABP was used in patients unable to be weaned from cardiopulmonary bypass by conventional means. Eighteen were weaned from the balloon, and 13 survived and were discharged from the hospital. In the 25 years since these initial reports nearly 5000 IABPs have been used at the Massachusetts General Hospital $(\mathrm{MGH})$. In this retrospective review we describe the evolution in indications, techniques, and results over this period.

\section{Patients and methods}

A total of 4756 cases of IABP insertion were registered in a log maintained by the cardiac procedures service. The hospital records of these patients were reviewed. The information abstracted from each record is shown in Appendix 1. The data fields were entered into a computerized database, prospectively since 1986 and retrospectively before that time.

The population reviewed encompassed all patients who were supported by an IABP from 1968 to June 1995. A subset of these (3097) underwent a cardiac surgical procedure during the same hospitalization. This cohort is referred to as the perioperative IABP group and includes patients in whom the balloon was placed before the operation (preoperative IABP), in the operating room during a cardiac surgical procedure (intraoperative IABP), or after the operation in the surgical intensive care unit (postoperative IABP). In a group of 193 consecutive patients who had intraoperative IABP insertions between 1985 and 1993, a further data set (Appendix 2) was obtained retrospectively and analyzed.

Multivariable probability models were constructed from the two sets of data with the use of BMDP program LR (BMDP Statistical Software, Inc, Los Angeles, Calif., Release 7,1992 ). The candidate variables for the models are shown in Appendices 1 and 2. The purpose of these models was to describe the risk factors for the outcome predicted. Accordingly, a reference specifying standards for the use of such models was applied in the analyses. ${ }^{9}$

Each model was fit with a stepwise forward stepping algorithm with the asymptotic covariance estimate used for entering variables into the model. In each step a variable was entered when the $F$ statistic to enter the variable had a tail-probability value less than 0.01 , and a variable was removed during a step when the tail-probability of the $F$ statistic to remove was more than 0.05 . Variables could enter or be removed twice from the model during the stepping. So that the data would not be overfitted, the stepping was stopped before the number of variables admitted into the model exceeded one tenth the number of events (deaths). To allow for nonconformity to a linear gradient among predictor variables, the continuous variables were divided into a small number of categoric ranges chosen from cross-tabulations against actual mortality and from clinicians' judgment of ranges likely to have different rates; for example, age was recoded into three categories: age less than 70 years, age between 70 and 80 years, and age more than 80 years.

Pairwise interactions among all candidate variables were entered as candidate predictors according to the hierarchical rule available in the logistic regression program; that is, no interaction could be entered into the model unless its two underlying variables were already in the model. No such interactions were found in either of our models (all that would have satisfied the criteria for entry would have required overfitting of the model to enter). The coding of all predictor variables is shown in the two appendices or in Tables IV and V. The program LR tests for collinearity of predictor variables, either by failing to converge when collinear variables are selected into the model or by attempting to remove a variable if a collinear variable is selected into the model. We found no such cases in our models. The problem of influential outlier variables was addressed by reviewing numerous crosstabulations of the data and by cross-checking the work of the data collection personnel. Data entry errors were caught and corrected in this manner.

The mathematical fit of each model was checked with the use of the Hosmer-Lemeshow goodness of fit $\chi^{2}$ test in the LR program. No model was accepted unless the tail $p$ value for this statistic was large $(>0.2)$. In addition, the areas under the receiver operator characteristic curves for the models were computed to assess the goodness of fit. For these models these are equivalent to the c-statistic or concordance index, the fraction of all pairs of patients, one survivor and one who died, for which the model predicted a higher probability of survival for the member of the pair who actually survived. ${ }^{10}$ The receiver operator characteristic areas were 0.78 for the overall mortality model and 0.89 for mortality among 193 patients supported with an IABP. Prospective validation of the probability models remains to be carried out, although modeling among a small number of random subsets of the patients produced similar results.

\section{Results}

To illustrate changes in some of the patterns of use, we divided the data into 5-year intervals (Table I). During the period studied, average patient age increased from 54 to 66 years and the percent of patients older than age 70 years increased from $2.1 \%$ to $38 \%$. Despite this, mortality fell from $41 \%$ to $20 \%$. The technique of insertion was initially $99 \%$ surgical via a femoral artery. In 1980 percutaneous insertion $^{11-13}$ was introduced, and in current practice $97 \%$ of balloons are placed percutaneously. Throughout this period, there has been a small incidence $(1.9 \%)$ of transthoracic balloon insertions via the ascending aorta when intraoperative balloon insertion is necessary and the femoral route in unsuccessful.

As the technique of balloon insertion has changed from surgical to almost exclusively percutaneous, the major geographic location of insertion has shifted from the intensive care unit or operating room to the cardiac catheterization laboratory. In 
Table I. Trends in LABP use divided into 5-year intervals (1968-1995)

\begin{tabular}{|c|c|c|c|c|c|c|}
\hline & $1968-75$ & $1976-80$ & $1981-85$ & $1986-90$ & $1991-95$ & Total \\
\hline Total & 430 & 718 & 950 & 1211 & 1447 & 4756 \\
\hline Mean age (yr) & 54.5 & 57.8 & 59.9 & 63.1 & 65.7 & 61.7 \\
\hline Percent older than 70 & 2.1 & 9.4 & 15.3 & 27.8 & 38.1 & 22.7 \\
\hline Percent male & 77.9 & 74.2 & 76.3 & 74.3 & 69.5 & 73.4 \\
\hline Percent mortality & 41.2 & 35.1 & 21.7 & 24.3 & 20.1 & 26 \\
\hline \multicolumn{7}{|l|}{ Method $(\%)$} \\
\hline Surgical & 99.7 & 93.2 & 28.2 & 8.3 & 2 & 31.4 \\
\hline Percutaneous & 0 & 1.8 & 69.2 & 91.2 & 96.5 & 66.7 \\
\hline Transthoracic & 0.2 & 5 & 2.6 & 0.5 & 1.5 & 1.9 \\
\hline \multicolumn{7}{|l|}{ Location $(\%)$} \\
\hline Cath lab & 2.1 & 6.7 & 64.6 & 75.1 & 82.7 & 58.4 \\
\hline OR & 25.1 & 42.8 & 23.7 & 14.5 & 11.9 & 20.8 \\
\hline MICU & 59.1 & 34 & 4.1 & 0.6 & 0 & 11.5 \\
\hline SICU & 9.8 & 9.9 & 4.1 & 5.1 & 4.6 & 5.9 \\
\hline Percent cardiac surgery & 73.3 & 84.5 & 69.5 & 60 & 54.5 & 65.1 \\
\hline Percent PTCA & 0 & 0 & 5.4 & 16.1 & 30.8 & 14.6 \\
\hline Percent vascular complications & 5.6 & 3.7 & 88 & 11.2 & 6.9 & 7.8 \\
\hline
\end{tabular}

$O R$, Operating room; $M I C U$, medical intensive care unit; SICU, surgical intensive care unit; $P T C A$, percutaneous transluminal coronary angioplasty.

Table II. Trends in indications for IABP

\begin{tabular}{ccccccc}
\hline Indication & $1968-75$ & $1976-80$ & $1981-85$ & $1986-90$ & $1991-95$ & Total \\
\hline Ischemia & 122 & 243 & 493 & 649 & $946^{*}$ & 2453 \\
$(\%)$ & $(28.4 \%)$ & $(33.8 \%)$ & $(51.9 \%)$ & $(53.6 \%)$ & $(65.4 \%)$ & $(51.6 \%)$ \\
Hemodynamic & 251 & 382 & 349 & 442 & $336^{*}$ & 1760 \\
$(\%)$ & $(58.4 \%)$ & $(53.2 \%)$ & $(36.7 \%)$ & $(36.5 \%)$ & $(23.2 \%)$ & $(37.0 \%)$ \\
\hline
\end{tabular}

Since 1975 the number of IABPs placed for hemodynamic decompensation (congestive heart failure, cardiogenic shock, or hypotension) has been relatively constant, whereas the number placed for ischemia has increased.

${ }^{*}$ Data are up to June 1995,7 months less than a full 5 years.

Table III. Complications of LABP

\begin{tabular}{lccc}
\hline & $\begin{array}{c}\text { Percutaneous } \\
(3168)\end{array}$ & $\begin{array}{c}\text { Transthoracic } \\
(90)\end{array}$ & $\begin{array}{c}\text { Surgical } \\
(1493)\end{array}$ \\
\hline Vascular & $10.2 \%$ & $0 \%$ & $5.4 \%$ \\
Infection & $0.1 \%$ & $0 \%$ & $1.4 \%$ \\
Balloon rupture/ & $1.7 \%$ & $4.4 \%$ & $0.3 \%$ \\
$\quad$ damage & & & \\
Passage failure & $0.4 \%$ & $3.3 \%$ & $4.8 \%$ \\
\hline
\end{tabular}

Complications of IABP use from 1968 to 1995 expressed as percent incidence. Infection for percutaneous IABP required positive blood cultures. In the surgical category, wound infections without positive blood cultures were included.

the past 5 years, $16 \%$ of balloons were placed in the operating room or intensive care unit as opposed to $87 \%$ in the late $1970 \mathrm{~s}$. With this change, the institution of IABP support has largely been transferred from the hands of the surgeon to those of the cardiologist.

A total of 3097 patients underwent cardiac surgery before, after, or concomitant with IABP insertion. Perioperative IABP usage has declined as a percentage of all IABPs from a high of $84 \%$ to $54 \%$ in the most recent interval. The percentage of patients undergoing angioplasty has gone from $0 \%$ to $31 \%$. Mortality for patients receiving IABP support and undergoing angioplasty was $14.7 \%$.

Although the number of patients supported by an IABP for hemodynamic decompensation (congestive heart failure, hypotension, and cardiogenic shock) has been fairly constant, support for ongoing ischemia has become much more frequent (Table II). The logistic and technical simplicity of percutaneous insertion had a major role in this trend. The mortality associated with IABP placement for ischemia over the entire series was $11.9 \%$ and for hemodynamic decompensation, $38.2 \%$.

In Table III the incidence of complications for the series as a whole is summarized. Because of the nature of a retrospective review, certain complications, particularly passage failure with percutaneous IABP, may be underreported. Balloon rupture has been more frequent in the recent era and is strongly influenced by age, presumably because of the in- 
Table IV. Multivariate predictors of death in all patients (medical and surgical) supported by an IABP from 1968 to 1995

\begin{tabular}{|c|c|c|c|}
\hline Multivariable predictors & $\begin{array}{c}\text { Odds ratio } \\
(O R)\end{array}$ & $\begin{array}{l}95 \% \text { lower } \\
\text { OR boundary }\end{array}$ & $\begin{array}{l}95 \% \text { upper } \\
\text { OR boundary }\end{array}$ \\
\hline \multicolumn{4}{|l|}{ Location } \\
\hline CCL (other risks relative to CCL) & 1 & & \\
\hline Operating room & 1.7 & 1.3 & 2.2 \\
\hline Medical ICU & 1.8 & 1.3 & 2.5 \\
\hline Surgical ICU & 1.7 & 1.2 & 2.3 \\
\hline Other & 2.7 & 1.1 & 6.7 \\
\hline Outside hospital & 1 & 0.6 & 1.6 \\
\hline \multicolumn{4}{|l|}{ Method } \\
\hline Surgical/graft (risk relative to this) & 1 & & \\
\hline Surgical/no graft & 1.2 & 0.8 & 1.7 \\
\hline Percutaneous & 0.8 & 0.6 & 1 \\
\hline Percutaneous through graft & 2 & 0.7 & 5.9 \\
\hline Transthoracic & 2.9 & 1.8 & 4.6 \\
\hline \multicolumn{4}{|l|}{ Age } \\
\hline Age $<70$ & 1 & & \\
\hline $70 \leq$ age $<80$ & 1.9 & 1.6 & 2.3 \\
\hline Age $\geq 80$ & 3.2 & 2.1 & 4.8 \\
\hline \multicolumn{4}{|l|}{ Procedure (risk relative to all other procedures) } \\
\hline Coronary artery bypass grafting & 0.5 & 0.4 & 0.6 \\
\hline Other & 2 & 1.4 & 2.7 \\
\hline Percutaneous transcoronary angioplasty & 0.6 & 0.4 & 0.7 \\
\hline \multicolumn{4}{|c|}{ Indications (risk relative to all other indications) } \\
\hline Ongoing ischemia & 0.5 & 0.4 & 0.6 \\
\hline Myocardial infarction & 1.6 & 1.3 & 2 \\
\hline Ventricular tachycardia/fibrillation & 2 & 1.6 & 2.5 \\
\hline Cardiogenic shock & 2.8 & 2.3 & 3.3 \\
\hline Congestive heart failure & 1.8 & 1.4 & 2.3 \\
\hline
\end{tabular}

$C C L$, Cardiac catheterization laboratory; $I C U$, intensive care unit.

creasing severity of calcific aortic atherosclerosis in older patients.

The independent predictors of mortality for all patients supported by IABP are shown in Table IV. Notable among these were insertion of the IABP in the operating room or intensive care unit, transthoracic insertion, age, procedure other than coronary artery bypass grafting or angioplasty, and insertion for cardiogenic shock. Placement for ongoing ischemia and for associated coronary artery bypass grafting or angioplasty were associated independently with a better outcome.

The results of the multivariate analysis of predictors of mortality in 193 intraoperative IABP insertions are shown in Table V. Mortality was $32 \%$ during this interval, slightly less than the $35.7 \%$ mortality for intraoperative insertion in the entire series. The independent predictors of death in these patients were age, mitral valve replacement, prolonged cardiopulmonary bypass, urgent or emergency operation, preoperative renal dysfunction, and complex ventricular ectopy or right ventricular failure after crossclamp removal. The timing of IABP insertion was important: placement after separation from bypass was associated with a better outcome than placement to wean from bypass; the outcome of placement after emergency reinstitution of bypass was worse. Postoperative acidosis and oliguria were associated with a higher risk of death.

\section{Discussion}

The evolution of demographics and practice observed conform with generalized trends throughout medicine toward improved results with less invasive treatment of more patients who are elderly.

There are two areas in which the data may be misleading. The first is the reduction in mortality observed over time despite the increasing age of the population. Some of this might reflect advances in critical care, surgery, and anesthesia as well as the inception of angioplasty, but there has also undoubtedly been a change in indications for IABP support such that the patients who are receiving IABP 
Table V. Multivariate predictors of death with LABP insertion during 193 cardiac surgical procedures between 1985 and 1993

\begin{tabular}{|c|c|c|c|}
\hline Multivariable predictors & $\begin{array}{l}\text { Odds ratio } \\
(O R)\end{array}$ & $\begin{array}{l}95 \% \text { lower } \\
\text { OR boundary }\end{array}$ & $\begin{array}{c}95 \% \text { upper } \\
\text { OR boundary }\end{array}$ \\
\hline \multicolumn{4}{|l|}{ Intraoperative IABP insertion timing } \\
\hline Necessary to come off CPB initially (risks relative to this) & 1 & & \\
\hline Emergency reinstitution of $\mathrm{CPB}$ for instability & 6.3 & 1.7 & 24 \\
\hline Off CPB before chest closure & 0.2 & 0.06 & 0.8 \\
\hline Off CPB after chest closure & 2.8 & 0.8 & 10 \\
\hline \multicolumn{4}{|l|}{ Preoperative assessment } \\
\hline Operation elective (risk relative to this) & 1 & & \\
\hline Operation urgent/emergency & 4.2 & 1.7 & 10.2 \\
\hline \multicolumn{4}{|l|}{ Procedure (risk relative to all other procedures) } \\
\hline Mitral valve replacement & 6.3 & 1.8 & 22 \\
\hline \multicolumn{4}{|l|}{ CPB time $(\min )$} \\
\hline Time $<100$ (risks relative to this) & 1 & & \\
\hline $100 \leq$ time $<150$ & 6.6 & 0.9 & 49 \\
\hline Time $\geq 150$ & 19 & 2.4 & 147 \\
\hline \multicolumn{4}{|l|}{ Preoperative creatinine } \\
\hline Creatinine $<1.5$ (risks relative to this) & 1 & & \\
\hline $1.5 \leq$ Creatinine $<2.0$ & 4.8 & 1.5 & 16 \\
\hline Creatinine $\geq 2.0$ & 6.2 & 1.8 & 21 \\
\hline \multicolumn{4}{|l|}{ Intraoperative CPB weaning problems* } \\
\hline Right ventricular dysfunction & 11 & 2.5 & 47 \\
\hline Complex ventricular ectopy & 15 & 2.9 & 80 \\
\hline
\end{tabular}

$C P B$, Cardiopulmonary bypass.

* Relative to all other problems and no problems.

support at the present time represent a less sick population (see Table II).

Second, there was an apparent increase in vascular complications with the introduction of percutaneous insertion in 1980 (see Table I). Whether this represents a true change in morbidity is questionable. For the purpose of this tabulation, vascular complications were defined as cases in which surgical treatment was required for limb ischemia, bleeding, or vessel injury. Mesenteric infarction, amputation, and aortic dissection were also included. Limb ischemia that resolved with balloon removal and localized arterial injury that did not require surgery were not included. This is a relatively narrow definition of vascular complications and probably understates their incidence compared with that reported in other series. ${ }^{11-17}$ With the change from surgical to percutaneous IABP insertion there was an immediate major reduction in the number of groin operations done overall, because a surgical balloon by definition requires an operation to place and remove the device whereas percutaneous insertion requires surgery only when there is a complication. More than $90 \%$ of percutaneous balloons are removed without the need for surgery, and the majority of vascular surgical procedures after per- cutaneous balloon removal are simple thrombectomies or patch angioplasties of no greater magnitude than surgical balloon placement or removal. Catastrophic vascular complications (iliac or aortic perforation, mesenteric infarction, amputation) have remained at less than $1 \%$ throughout the series after initially appearing to be more frequent with the first 100 balloons placed by the percutaneous technique. ${ }^{17}$

In recent years, surgical series from St. Louis University and Washington University ${ }^{18,19}$ have reported institutional patterns of IABP use and associated mortality. In Table VI the last 15 years of our data on perioperative IABP use at the MGH are displayed with data from these other series. The rate of IABP use as a percentage of all cardiac operations was higher at the MGH: $12.3 \%$ versus 8.5 and $9.8 \%$. A higher percentage of perioperative balloons were placed before the operation in our series $(70.6 \%$ vs $35.7 \%$ and $18.8 \%$ of perioperative balloons). Intraoperative and postoperative IABP use was correspondingly less frequent at the MGH $(3.6 \%$ of all cardiac operations vs $6.3 \%$ and $6.8 \%$ ). This strong bias toward early balloon insertion is an established tenet of cardiology practice at the MGH because the decision to place a balloon more frequently occurs at the time of catheterization before surgical consultation. 
Table VI. Comparison with other surgical series

\begin{tabular}{|c|c|c|c|c|}
\hline Institution & $\begin{array}{l}\text { Cardiac } \\
\text { operations }\end{array}$ & $\begin{array}{c}\text { Percent operations } \\
\text { with periop. } \\
L A B P\end{array}$ & $\begin{array}{c}\text { Percent of periop. } \\
\text { IABP placed } \\
\text { preop. }\end{array}$ & $\begin{array}{l}\text { Percent mortality } \\
\text { for all periop. } \\
\qquad A B P P\end{array}$ \\
\hline MGH (1980-95) & 17,678 & $\begin{array}{c}2175 \\
(12.3 \%)\end{array}$ & $\begin{array}{c}1535 \\
(70.6 \%)\end{array}$ & $\begin{array}{c}16.3 \% \\
(95 \% \text { CI: } 14.7 \% \text { to } 17.9 \%)\end{array}$ \\
\hline Washington Univ. (1986-91) & 6,856 & $\begin{array}{c}672 \\
(9.8 \%)\end{array}$ & $\begin{array}{c}240 \\
(35.7 \%)\end{array}$ & $\begin{array}{c}28.7 \% \\
(95 \% \text { CI: } 25.3 \% \text { to } 32.1 \%)\end{array}$ \\
\hline St Louis Univ. (1982-90) & 6,877 & $\begin{array}{l}580 \\
(8.5 \%)\end{array}$ & $\begin{array}{c}107 \\
(18.4 \%)\end{array}$ & $\begin{array}{c}44.0 \% \\
(95 \% \text { CI: } 40 \% \text { to } 48 \%)\end{array}$ \\
\hline
\end{tabular}

At MGH, a higher percentage of cardiac surgical cases had an IABP. A greater percentage of these IABPs were placed preoperatively. (Comparison made by $\chi^{2}$ tests with two degrees of freedom). $C I$, confidence interval.

Table VII. Outcomes with perioperative LABP in the percutaneous era (mortality since 1980)

\begin{tabular}{lcccc}
\hline & Cath lab & OR & SICU & Total \\
\hline Number of patients & 1168 & 435 & 198 & 2175 \\
Deaths & 117 & 128 & 66 & 354 \\
Mortality rate & $10.0 \%$ & $29.4 \%$ & $33.3 \%$ & $16.3 \%$ \\
& $(95 \%$ CI: $8.3 \%$ to $11.7 \%)$ & $(95 \%$ CI: $25 \%$ to $33.8 \%)$ & $(95 \%$ CI: $27 \%$ to $40 \%)$ & $(95 \%$ CI: $14.7 \%$ to $17.9 \%)$ \\
\hline
\end{tabular}

The mortality rate of preoperative IABP usage was one third that of an intraoperative or postoperative IABP. OR, Operating room; SICU, surgical intensive care unit; $C I$, confidence interval

Although the association cannot be proved to be causal, the mortality associated with this practice is lower $(16.3 \%$ vs $28.7 \%$ and $44.0 \%)$, and it is our impression that liberal use of IABP support to stabilize medically refractory ischemia in the preoperative interval reduces overall surgical mortality (Table VII). Our preference has been to allow 24 to 48 hours of IABP support to quiet unstable or postinfarction angina and permit recovery of ischemic myocardium before operation as opposed to undertaking an immediate operation in the setting of ongoing ischemia. Persistent angina, hemodynamic instability, or limb-threatening ischemia in the leg into which the balloon was inserted may still necessitate an emergency operation in some instances. Others ${ }^{20}$ have noted the efficacy of early IABP therapy in surgical patients with unstable coronary syndromes. A reduction in mortality in patients having emergency/urgent coronary bypass grafting from $31 \%$ to $0 \%$ was associated with an increase in preoperative IABP use from $24 \%$ to $89 \%$ of these cases.

It is possible that the lower mortality associated with preoperative balloon use may reflect a propensity to use IABP support prophylactically in stable patients with high-risk anatomy. This can have only a modest influence, because just $7 \%$ of our perioperative insertions since 1980 have been prophylactic, with an $11 \%$ mortality rate, which is not lower than that of other patients receiving preoperative IABP support. Finally, it is unlikely that these results can be attributed to recent advances in myocardial protection, because the techniques used at the MGH in the cases reported are a mixture of the spectrum of methods through the history of cardiac surgery, including hypothermic fibrillatory arrest, crystalloid cardioplegia, cold blood cardioplegia, and warm continuous blood cardioplegia.

Given that one of the areas in which mortality remains highest is the subgroup of patients undergoing balloon insertion during and after heart surgery, it is logical to ask whether intervention with a ventricular assist device (VAD) in some of these patients might produce a better outcome. Previous attempts $^{21,22}$ at determining which patients are at greatest risk of death with intraoperative IABP insertion include a prospectively validated model developed by Baldwin, Slogoff, and Noon. ${ }^{22}$ Their model describes the need for pacing, preoperative renal dysfunction, advanced age, female sex, and prolonged cardiopulmonary bypass as positive predictors of death. Our analysis had similar findings although sex was not found to be an independent predictor. Among the other variables we found not to be predictive of mortality with IABP insertion were preoperative or postoperative myocardial infarction, number or dose of inotropic agents, preoperative left ventricular function, cardiac output before or after the operation, peripheral vascular disease, diabetes, reoperation, and left main disease. 
The independent predictors of death with intraoperative insertion shown in Table $\mathrm{V}$ can be combined into a prediction formula that has an $80 \%$ sensitivity and specificity in this retrospective population but has not been prospectively validated. The practical usefulness of such a model is limited in that some of the predictive elements are generalized risk factors for death after heart surgery and do not clarify which portion of the population at risk is most likely to be salvaged by VAD support. For example, elderly patients with prior renal dysfunction and long bypass runs may be just as likely to do poorly with VAD support as with an IABP. Ideally, we would like to be able to identify the subgroup of patients who are both at high risk of death with IABP and have the best likelihood of survival with a VAD.

Theoretically, the subset of patients that would be best served by temporary VAD support are those with profound hemodynamic compromise but a technically corrective cardiac operation with reversible injury. In our limited institutional experience, 14 patients were supported with a VAD after cardiac operations between 1986 and 1995. Four were successfully bridged to transplantation, and three of these survived. A fifth patient was weaned from the $\mathrm{VAD}$ and is a long-term survivor. As experience with VAD support after cardiotomy is acquired in greater numbers, the question can be addressed more substantially.

In conclusion, the use of IABP support has steadily become more prevalent although still with a significant associated mortality and complication rate. The data presented are limited by being uncontrolled and retrospective, but it is our impression that liberal preoperative balloon use to quiet unstable coronary syndromes can reduce surgical mortality and the need for IABP placement during and after the operation. The risk of death with IABP use remains high, but models to predict death in this setting may not identify the best candidates for VAD support.

\section{REFERENCES}

1. Clauss RH, Birtwell WC, Albertal G. Assisted circulation. I. The arterial counterpulsator. J Thorac Cardiovasc Surg 1961; 41:447-58.

2. Moulopoulos SD, Topaz S, Kolff WJ. Diastolic balloon pumping (with carbon dioxide) in the aorta: a mechanical assistance to the failing circulation. Am Heart J 1962;63:66975.

3. Powell WJ Jr, Daggett WM, Magro AE. Effects of intraaortic balloon counterpulsation on cardiac performance, oxygen consumption and coronary blood flow in dogs. Circ Res 1970;26:753.

4. Bolooki H. Physiology of balloon pumping. In: Bolooki $\mathrm{H}$, editor. Clinical application of the intra-aortic balloon pump. Mt. Kisco [NY]: Futura, 1984:57-126.

5. Kantrowitz A, Tjonneland S, Freed PS. Initial clinical experience with intraaortic balloon pumping in cardiogenic shock. JAMA 1968;203:135-40.

6. Buckley MJ, Leinbach RC, Kastor JA. Hemodynamic evaluation of intraaortic balloon pumping in man. Circulation 1970;41,42:130-36.

7. Kantrowitz A. Origins of intraaortic balloon pumping. Ann Thorac Surg 1990;50:672-4.

8. Buckley MJ, Craven JM, Gold HK. IABP assist for cardiogenic shock after cardiopulmonary bypass. Circulation 1972; 46(Suppl):II76.

9. Concato J, Feinstein AR, Holford TR. The risk of determining risk with multivariable models. Ann Intern Med 1993; 118:201-10.

10. Braitman LE, Davidoff F. Predicting clinical states in individual patients. Ann Intern Med 1996;125:406-12.

11. Bregman D, Nichols AB, Weiss MB, et al. Percutaneous intraaortic balloon insertion. Am J Cardiol 1980:46;261-4.

12. Subramanian VA, Goldstein JE, Sos TA, et al. Preliminary clinical experience with percutaneous intraaortic balloon pumping. Circulation 1980;62(Suppl)I123-9.

13. Leinbach RC, Goldstein J, Gold HK. Percutaneous wireguided balloon pumping. Am J Cardiol 1982:49:1707-10.

14. McEnany MT, Kay HR, Buckley MJ. Clinical experience with intraaortic balloon pump support in 728 patient. Circulation 1978;58:3:I124-31.

15. Pinkard J, Utley JR, Leyland SA, Relative risk of aortic and femoral insertion of intraaortic balloon pump after coronary artery bypass grafting procedures. J Thorac Cardiovase Surg 1993;105:721-8.

16. Barnett MG, Swartz MT, Peterson GJ. Vascular complications from intraaortic balloons: risk analysis. J Vase Surg 1994;19:81-9.

17. Martin RS, Moncure AC, Buckley MJ. Complications of percutaneous intra-aortic balloon insertion. J Thorac Cardiovasc Surg 1983;85:186-90.

18. Creswell LL, Rosenbloom M, Cox JL. Intraaortic balloon counterpulsation: patterns of usage and outcome in cardiac surgery patients. Ann Thorac Surg 1992;54:11-20.

19. Naunheim KS, Swartz MT, Pennington DG. Intraaortic balloon pumping in patients requiring cardiac operations: risk analysis and long-term follow-up. J Thorac Cardiovasc Surg 1992;104:1654-61.

20. Dziuban SW, McIlduff JB, Miller SJ. How a New York cardiac surgery program uses outcomes data. Ann Thorac Surg 1994:58:1871-6.

21. Pi K, Block PC, Warner MG. Major determinants of survival and nonsurvival of intraaortic balloon pumping. Am Heart $\mathrm{J}$ 1995;130:849-53.

22. Baldwin RT, Slogoff S, Noon GP. A model to predict survival at time of postcardiotomy intraaortic balloon pump insertion. Ann Thorac Surg 1993:55:908-13.

\section{Discussion}

Dr. D. Glenn Pennington (Winston-Salem, N.C.). Dr. Torchiana and his colleagues at the MGH have presented a superb report of one of the oldest and largest IABP 
experiences in the world, and they have demonstrated an encouraging decline in the overall mortality and vascular complication rate. Furthermore, their criteria for use indicate a dramatic decrease in the hemodynamic indication and a sharp increase in the indication for unstable angina, a fact that probably accounts for most of the improvement in the mortality rate.

Our interest centers more around the group of patients who required IABPs in conjunction with cardiac surgery. The authors report a higher frequency of perioperative use, $12 \%$, than most other centers. Moreover, more than $70 \%$ of the cardiac surgery IABPs were placed before the patient was taken to the operating room. We assume that most of those patients were not in cardiogenic shock and had balloons placed prophylactically or to stabilize unstable angina. Might some of these patients without hemodynamic compromise have done just as well without a balloon? However, hemodynamic stabilization of patients before coming to the operating room makes inherently good sense, and this practice has probably been underused in many of our centers. We are indebted to the MGH group for bringing this to our attention.

Because a large number of our patients are currently referred for unstable angina, I wish to ask what criteria should be used in a patient group with such wide variations. If every patient with so-called unstable angina received an IABP before the operation, the cost would become significant.

In the last subset of patients analyzed, there are 193 patients who did receive their balloons in the operating room or intensive care unit. In this group the $32 \%$ mortality rate was more in keeping with that reported from other centers. The authors tried to determine whether VADs might have been more helpful than IABPs in this group, and they could project a potential $40 \%$ survival in this group if they had received VADs. Perhaps that would be significant. In any case, I believe that the $32 \%$ mortality rate in patients requiring operative IABP placement is still unacceptable and that we are obligated to evaluate the effect of a more complete form of circulatory support, such as a VAD, in these desperately ill patients.

I would put forward four questions. One, how many of the patients without hemodynamic compromise might have done well without IABPs? Two, which patients with unstable angina should receive preoperative IABPs? Three, what role should VADs play? Four, would the authors support a randomized study of IABP versus VAD for patients requiring intraoperative support for hemodynamic compromise?

Dr. Torchiana. I would like to thank Dr. Pennington for his questions. The answers to these questions are a matter of opinion and practice rather than a matter of definitive fact. I think the fact that the percentage of balloons used at $\mathrm{MGH}$ is around a quarter to a third higher than at other comparable institutions but the mortality rate significantly lower suggests that we are not overusing balloons, but, rather, that they are being underused in the preoperative period at other institutions. Undoubtedly, a certain per centage of patients brought to the operating room at our institution with a preoperative IABP did not need to have it placed. However, prophylactic use is not a major indication for balloon use at our institution, because only $7 \%$ of the patients in this report had prophylactic balloons.

In general, the major use of the balloon was for the stabilization of unstable angina. These are patients in whom angina cannot be controlled by intravenous nitroglycerin and other attempts at medical therapy. If a balloon is placed in these patients and the angina subsides, it is our conviction that allowing the patient 24 to 48 hours of IABP support rather than an immediate operation is preferable.

Which patients might best be benefited by a VAD insertion in the operating room is a difficult question. When you identify the patients most likely to die with an IABP insertion, you have really identified a very sick group of patients who are unlikely to do well with a VAD either. The most logical way to approach this, as Dr. Pennington suggests, is to randomize the insertion of an IABP or a VAD in this group.

Dr. Robert A. Guyton (Atlanta, Ga.). I lived in the MGH from 1970 until 1980 and think that I have probably inserted 100 or so of these balloons. My question has to do with the patients who had balloons inserted who did not come to the operating room. You report between 1980 and the present a $16 \%$ mortality in patients who were operated on with IABP support, but you report about a $21 \%$ mortality overall for balloon usage. That means that the mortality of the patients who had the balloon inserted and did not go to the operating room must be $30 \%$ or $35 \%$. Did patients, for example, who had a major catastrophe at the time of IABP insertion in the preoperative period not get operated on and therefore not enter into the numerator of your perioperative deaths of patients with IAPBs?

Dr. Torchiana. That is an excellent point, Dr. Guyton, and I do not think there is any way that I can prove or refute what you are saying. The patients in whom a balloon is placed who do not respond with relief of ischemia or patients in whom a balloon is placed for an acute mechanical complication of myocardial infarction, like papillary muscle rupture or postinfarction ventricular septal defect, go immediately to the operating room, as do patients with a balloon in an ischemic limb. Those groups are not turned away from surgical treatment. However, I agree that it is possible that surgical selection is at play and some patients who receive an IABP and do very, very badly therefore die without surgical treatment. Yours is a valid observation and probably may still be the correct way to do things. Not all patients in whom a balloon is placed are candidates for surgery.

For appendixes see pages 766-9. 
Appendix 1. Data form for all balloon insertions, 1968 to 1995

\begin{tabular}{|c|c|}
\hline \multicolumn{2}{|l|}{ Field names and entry options } \\
\hline LOCATION & \\
\hline 1 Cardiac catheterization laboratory & 09 Percutaneous translummal coronary angioplasty \\
\hline 2 Operating room & 10 Percutaneous aortic valvuloplasty \\
\hline 3 Medical intensive care unit & 11 Percutaneous mitral valvuloplasty \\
\hline 4 Surgical intensive care unit & INDICATION \\
\hline 5 Emergency ward & 01 Support in cardiac catheterization laboratory \\
\hline 6 Other & 02 Support after cardiopulmonary bypass \\
\hline 7 Outside hospital & 03 Ongoing ischemia \\
\hline & 04 Myocardial infarction \\
\hline INSERTION SITE & 05 Ventricular septal rupture \\
\hline 1 Left femoral & 06 Mitral regurgitation \\
\hline 2 Right femoral & 07 Ventricular arrhythmias \\
\hline 3 Transthoracic & 08 Prophylactic \\
\hline & 09 Hypotension \\
\hline SEX & 10 Cardiogenic shock \\
\hline 1 Male & 11 Congestive heart failure \\
\hline 2 Female & INSERTION TIMING \\
\hline SUCCESS & 1 Before catheterization \\
\hline 1 Yes & 2 During catheterization \\
\hline $0 \mathrm{No}$ & 3 After catheterization \\
\hline CATHETER SIZE & 4 Preoperative \\
\hline $19 \mathrm{~F}$ & 5 Intraoperative \\
\hline $29.5 \mathrm{~F}$ & 6 Postoperative \\
\hline $310.5 \mathrm{~F}$ & 7 IABP only \\
\hline $411 \mathrm{~F}$ & COMPLICATION \\
\hline $512 \mathrm{~F}$ & 01 Perforation of arterial wall \\
\hline $614 \mathrm{~F}$ & 02 Dissection of local artery \\
\hline & 03 Passage failure \\
\hline IABP SIZE & 04 Bleeding at insert site \\
\hline $140 \mathrm{ml}$ & 05 Infection at insert site \\
\hline $230 \mathrm{ml}$ & 06 Infection with positive blood culture \\
\hline $320 \mathrm{ml}$ & 07 Embolus \\
\hline MANUFACTURER & 08 Balloon rupture \\
\hline $1 \mathrm{AVCO} / \mathrm{Kontron}$ & 09 Damage to IABP catheter \\
\hline 2 Aires/St. Jude Medical & 10 Loss of pulse, IABP removal \\
\hline 3 Datascope & 11 Loss of pulse, vascular surgery after removal \\
\hline 4 Mansfield & 13 Arteriovenous fistula \\
\hline 5 Other & 14 Loss of limb \\
\hline PREVIOUS IABP & 15 False aneurysm \\
\hline 1 Yes & 16 Iliac perforation \\
\hline $0 \mathrm{No}$ & 17 Laceration \\
\hline & 18 Mesenteric infarction \\
\hline AORTOILIAC ANGIOGRAM & 19 Thrombosis \\
\hline 1 Yes & 20 Above-knee amputation \\
\hline 0 No & 21 Below-knee amputation \\
\hline DEATH & 22 Other \\
\hline 1 Yes & CAUSE OF DEATH \\
\hline 0 No & 1 Myocardial infarction \\
\hline METHOD & 2 Congestive heart failure \\
\hline 1 Surgical graft & 3 Arrhythmia \\
\hline 2 Surgical/no graft & 4 Noncardiac \\
\hline 3 Percutaneous & TIMING OF DEATH \\
\hline 4 Percutaneous through graft & 1 Before catheterization \\
\hline PROCEDURE & 2 During catheterization \\
\hline 01 Coronary bypass & 3 After catheterization \\
\hline 02 Mitral valve replacement or repair & 4 Preoperative \\
\hline 03 Aortic valve replacement & 5 Intraoperative \\
\hline 04. Tricuspid valve replacement or repair & 6 Postoperative \\
\hline 07 Reoperation & 7 After IABP \\
\hline 08 Other & \\
\hline 05 Left ventricular aneurysmectomy & \\
\hline 06 Repair ventricular septal rupture & \\
\hline
\end{tabular}


Appendix 2. LABP insertion data form

\begin{tabular}{|c|c|}
\hline Field name & Entry option \\
\hline \multicolumn{2}{|l|}{ Sex } \\
\hline \multicolumn{2}{|l|}{ Age } \\
\hline \multirow[t]{8}{*}{ Intraoperative $\mathrm{CPB}$ weaning problems } & Low resistance state \\
\hline & Left ventricular dysfunction \\
\hline & Right ventricular dysfunction \\
\hline & Rhythm dysfunction \\
\hline & Valvular dysfunction \\
\hline & Complex ventricular ectopy \\
\hline & Atrial conduction abnormality \\
\hline & Electrocardiographic ischemic changes \\
\hline \multirow[t]{8}{*}{ Intraoperative reason for IABP } & Low resistance state \\
\hline & Left ventricular dysfunction \\
\hline & Right ventricular dysfunction \\
\hline & Rhythm dysfunction \\
\hline & Valvular dysfunction \\
\hline & Complex ventricular ectopy \\
\hline & Atrial conduction abnormality \\
\hline & Electrocardiographic ischemic changes \\
\hline \multirow[t]{4}{*}{ Intraoperative $\mathrm{IABP}$ insert timing } & Necessary to come off CPB initially \\
\hline & Emergency reinstitution of CPB for instability \\
\hline & Off CPB before chest closure \\
\hline & Off $\mathrm{CPB}$ after chest closure \\
\hline \multicolumn{2}{|l|}{ Postoperative myocardial infarction } \\
\hline \multicolumn{2}{|c|}{ Postoperative metabolic function $>1$} \\
\hline \multicolumn{2}{|c|}{ Bicarbonate in first 8 hours in intensive care unit } \\
\hline \multirow[t]{2}{*}{ Postoperative renal function } & Normal \\
\hline & Oliguria/anuria ( $<30 \mathrm{ml} / \mathrm{hr}$ for $>2 \mathrm{hr}$ consecutively) \\
\hline \multirow[t]{2}{*}{ Postoperative pulmonary function } & Normal \\
\hline & Hypoxemia $\left(\mathrm{PO}_{2}<100\right.$ on $\left.100 \% \mathrm{FiO}_{2}\right)$ \\
\hline \multicolumn{2}{|r|}{ - } \\
\hline \multicolumn{2}{|l|}{ Discharge date } \\
\hline \multicolumn{2}{|l|}{ Surgery date } \\
\hline \multicolumn{2}{|l|}{ IABP removal date } \\
\hline \multicolumn{2}{|l|}{ Surgeon } \\
\hline \multicolumn{2}{|l|}{ Mortality } \\
\hline \multirow[t]{3}{*}{ IABP route } & Percutaneous femoral \\
\hline & Surgical femoral \\
\hline & Transthoracic \\
\hline \multirow[t]{3}{*}{ Status at surgery } & Elective \\
\hline & Emergency \\
\hline & Urgent \\
\hline \multirow[t]{4}{*}{ Preoperative left ventricular function } & Normal \\
\hline & Isolated dysfunctional region \\
\hline & Diffuse mild/moderate hypokinesis \\
\hline & Severe dysfunction. \\
\hline Preoperative ejection fraction & \\
\hline Preoperative cardiac output & \\
\hline Preoperative cardiac index & \\
\hline Properative pulmonary capillary wedge $\mathrm{p}$ & \\
\hline Preoperative condition & Unremarkable \\
\hline & Myocardial infarction $<7$ days \\
\hline & Ischemia $<24 \mathrm{hr}$ preop. \\
\hline & $\begin{array}{l}\text { Cardiopulmonary resuscitation on arrival in operating } \\
\text { room }\end{array}$ \\
\hline & Pressor use before operating room \\
\hline & Intravenous heparin \\
\hline & Intravenous nitroglycerin \\
\hline & Diuretic need \\
\hline & Myocardial infarction 7-30 days \\
\hline
\end{tabular}


Appendix 2. Continued

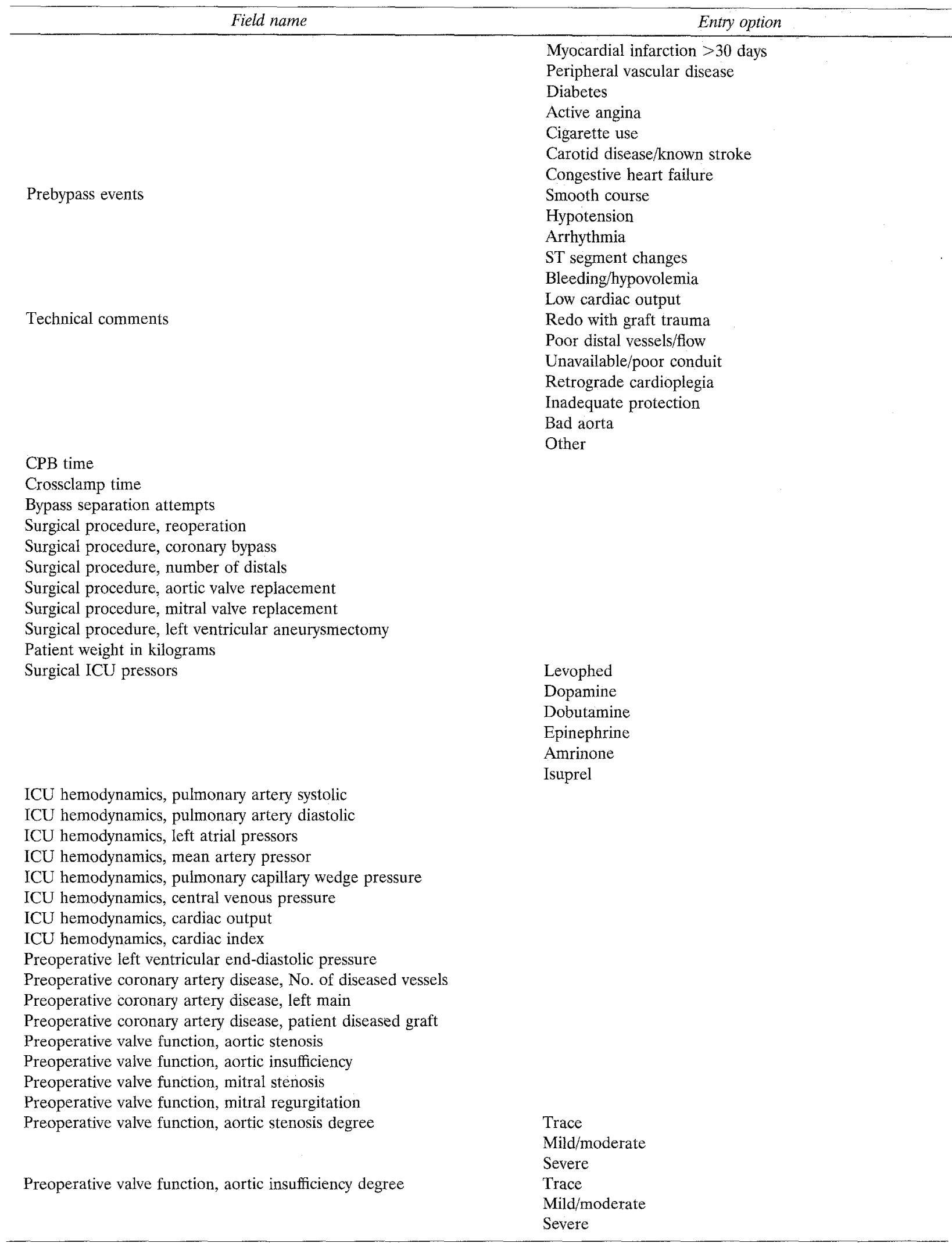




\section{Appendix 2. Continued}

\begin{tabular}{ll}
\hline \multicolumn{1}{c}{ Field name } & Entry option \\
\hline Preoperative valve function, mitral regurgitation degree & Trace \\
& Mild/moderate \\
& Severe \\
IABP removal complication, bleeding & \\
IABP removal complication, vascular surgery & \\
Preoperative creatinine & \\
\hline
\end{tabular}

$C P B$, Cardiopulmonary bypass; $I C U$, intensive care unit.

\section{Availability of Journal back issues}

As a service to our subscribers, copies of back issues of The Journal of Thoracic and Cardiovascular Surgery for the preceding 5 years are maintained and are available for purchase from Mosby at a cost of $\$ 15.00$ per issue until inventory is depleted. The following quantity discounts are available: $25 \%$ off on quantities of 12 to 23 , and one third off on quantities of 24 or more. Please write to Mosby-Year Book, Inc., Subscription Services, 11830 Westline Industrial Drive, St. Louis MO 63146-3318, or call 800-453-4351 or 314-453-4351 for information on availability of particular issues. If unavailable from the publisher, photocopies of complete issues may be purchased from UMI, 300 N. Zeeb Rd., Ann Arbor, MI 48106, 313-761-4700. 